\title{
LAS DANZAS EN LA REPRESENTACIÓN CULTURAL ESPAÑOLA DE AMÉRICA Y ÁFRICA: MESTIZAJE MUSICAL EN SEVILLA EN LOS SIGLOS XVI Y XVII ${ }^{1}$
}

\author{
Clara Bejarano Pellicer \\ UNIVERSIDAD DE SEVILLA
}

\begin{abstract}
RESUMEN
Los contactos con América y África proyectaron una influencia sobre la cultura musical española que en la Sevilla de los siglos XVI y XVII se refleja en la danza. Este trabajo realiza una aproximación al impacto producido por la interacción de estos continentes y las influencias musicales recibidas por Sevilla a través del Atlántico. A través de las manifestaciones coreomusicales mejor documentadas, se indaga acerca del alcance, difusión y cauces del sincretismo cultural intercontinental que tuvo lugar en Sevilla en este primer período de contacto.
\end{abstract}

\section{ABSTRACT}

The contact with America and Africa projected influences on Spanish musical culture that the dance shows in Seville in XVIth and XVIIth centuries. This paper does an approachment to the impact caused by the interaction with these continents and the musical influences received by Seville across the Atlantic ocean. Through the best documented choreo-musical events, we search on the significance, spreading and course of intercontinental cultural syncretism happened in Seville in this first period of contact.

PALABRAS CLAVE: danza, Corpus, sincretismo, indios, negros KEY WORDS: dance, Corpus Christi, syncretism, Indians, Blacks

1. Trabajo que se inscribe en el Proyecto I+D "Andalucía en el mundo atlántico: actividades económicas, realidades sociales y representaciones culturales (siglos XVI-XVIII)". HAR2013-41342-P. Dicho Proyecto está financiado por la Subdirección General de Proyectos de Investigación del Ministerio de Economía y Competitividad. 
El descubrimiento de América constituyó el detonante de un proceso de globalización que puso en contacto el devenir de, al menos, tres continentes hasta entonces independientes. Al entroncar sus historias, comenzó un largo y trascendental flujo de intercambios multilaterales que se manifestaron en todos los órdenes. Uno de los ámbitos en los que se produjo mestizaje cultural fue el musical, como no podía suceder de otro modo.

Existen sólidas aportaciones sobre las consecuencias musicales que supuso el descubrimiento de América para este continente. La implantación del sistema de capillas catedralicias en territorio indiano tomando como modelo a las andaluzas ha prosperado mucho, no sólo entre la musicología española sino también la americana ${ }^{2}$. A su vez ha copado no poco interés el papel de la música en las reducciones jesuitas ${ }^{3}$. Asimismo, la rápida difusión del repertorio europeo ha sido rastreada en toda la geografía del Nuevo Mundo ${ }^{4}$. Lo que apenas se ha investigado es cuáles fueron las novedades que esta conexión intercontinental supuso para las estructuras musicales del Viejo Mundo. Recientemente se ha acometido la investigación sobre las migraciones de músicos españoles a América y las oportunidades que las Indias inyectaron a la carrera profesional de los mismos ${ }^{5}$. No obstante, hay mucho que hacer sobre el sincretismo musical propiamente dicho. Aunque existen magníficas aportaciones conceptuales y referentes a la Contemporaneidad procedentes de la Etnomusicología ${ }^{6}$, no hay muchas aproximaciones históricas al período moderno más allá de las obras clásicas de Stevenson y Claro Valdés ${ }^{7}$. Especialmente pasan desapercibidas las influencias americanas que penetran en Europa, más que viceversa.

Esta concepción unidireccional de las relaciones musicales resultaría injusta, proyectando una imagen de superioridad cultural europea, además de inverosímil. Este trabajo se propone una aproximación, hasta donde las fuentes más ligadas al tema lo permiten, al impacto que causaron en las manifesta-

2. Citemos como ejemplo las siguientes aportaciones: G. BAKER (2005), 177-190.

3. Algunos de los trabajos en esta línea son: L.J. Waisman (2005), 159-175. G. WiLde (2010), 103-112.

4. M. GeMBero Ustárroz (2007a), 147-177.

5. Un grupo de investigación subvencionados por el Ministerio de Educación y Cultura ("Proyección musical de España en América, 1492-1898") y dos por la Junta de Andalucía ("La música en el Archivo General de Indias" y "Mecenazgo musical en Andalucía y su proyección en América"), a cargo de la profesora María Gembero Ustárroz, han marcado un hito a la hora de profundizar y rastrear fuentes en este sentido. M. GEMBERo UsTáRroz (2000), 128-142. M. Gembero UstárRoZ (2007b), 17-58.

6. Como las obras de V. Eli Rodríguez (2009a), 43-58 y (2009b), 270-311.

7. Por ejemplo, E. BermúdeZ (1995). 
ciones musicales españolas las primeras y estrechas relaciones con América y África. Este acercamiento a un objetivo tan ambicioso como el referido tiene como sujeto de estudio concreto las huellas de las relaciones entre España, África y América en la actividad coreográfica de los siglos XVI y XVII en Sevilla. Pensamos que la danza puede contribuir a poner de relieve que el flujo cultural no fue unidireccional, sino que la cultura musical española también experimentó un enriquecimiento gracias a sus contactos con África y América. Se trata de una actividad, más social que artística en aquellos tiempos, que vivió un momento de desarrollo en este marco cronológico y por ello ha dejado a la posteridad un volumen de información que, aunque nunca nos parezca suficiente dadas las dificultades para reconstruir una disciplina escénica sin sistemas de notación satisfactorios, resulta más rico que el de otros períodos. En cualquier caso, al ser una actividad perceptible por el sentido de la vista, los testimonios son más numerosos y gráficos que los referentes al sincretismo musical propiamente dicho, y pueden contribuir a clarificar aspectos referentes a este proceso.

La ciudad hispalense constituye un excelente observatorio para la fermentación de las influencias africanas y americanas en la cultura europea, debido a su condición de cauce de los flujos intercontinentales. En Sevilla tuvieron lugar los primeros contactos entre culturas y sus primeros frutos, conceptuales y artísticos, en el imaginario colectivo español. La dinámica sociedad hispalense actuó como una cabeza de puente de las profundas huellas que habría de dejar la aventura atlántica en la historia andaluza y española, en lo musical tanto como en cualquier otro parámetro. La delimitación cronológica del estudio responde a factores de orden práctico -las transformaciones en materia coreográfica fueron tan sensibles que produjeron una masa de información coetánea, en un período dorado para el desarrollo de este arte en España-, y de orden conceptual, pues aunque las influencias nunca dejaron de circular entre España y América, en los primeros siglos de contacto tuvieron que ser más perceptibles y fértiles.

Así pues, esta aportación se plantea preguntas en torno a la recurrencia y difusión de América y África como temática de las manifestaciones coreo-musicales que tuvieron lugar en Sevilla en este período. A su vez, indagamos sobre los medios de caracterización musical que se emplearon para abordar estos temas. Lo cual debería llevarnos a los cauces a través de los cuales se adquirieron dichos medios, y también a la participación directa de africanos y americanos en estas actividades artísticas hispalenses. En definitiva, se trata de valorar si se produce un sincretismo cultural en la danza en el plano estético 
o si se limita a aportaciones conceptuales, y qué alcance podemos atribuirle. Por razones discursivas, empezaremos tratando las aportaciones americanas para luego pasar a las africanas, aunque cronológicamente debiera ser a la inversa.

Puesto que las danzas del Siglo de Oro constituyen un tema sobre el cual ya se han realizado magníficos estudios de base, reuniendo ingente cantidad de información ${ }^{8}$. Este trabajo apenas acudirá a las fuentes originales, sino que se apoyará en las bases de datos disponibles y la bibliografía publicada para llevar a cabo una reflexión teórica desde un punto de vista en el que no se ha profundizado como enfoque.

\section{LAS DANZAS DEL CORPUS EN SEVILLA}

Quizá lo primero que debamos abordar es cuáles son las evidencias musicales del impacto que causó a los europeos, concretamente a los españoles, el descubrimiento del Nuevo Mundo. Al margen de las observaciones que plasmasen los cronistas sobre las prácticas musicales de los indígenas, la impresión que en los españoles había causado el repentino ensanche del mundo tuvo su reflejo más inmediato en la rápida inclusión de los habitantes de América en la representación geo-musical de la Tierra.

¿Dónde tenía lugar dicha representación? Anualmente, las ciudades más importantes de la península Ibérica incluían en la procesión general del Corpus Christi una serie de compañías de danza a costa del concejo municipal. Esta costumbre, heredada de los gremios que hasta 1554 contribuyeron a la procesión hispalense, incluía un premio o joya otorgada a la mejor danza, de ahí que las compañías contratadas compitieran entre sí en originalidad y vistosidad. Las más populares y dinámicas de las danzas que se representaron durante la Edad Moderna fueron denominadas de invención, esto es, teatralizadas. A diferencia de las danzas que no eran de invención, cada año cambiaban su argumento, su música, su vestuario y su coreografía, superándose en nivel técnico y creatividad 9 . Una gran contribución al fomento de estas fiestas fue concertarlas mediante subasta pública en que se obligaba a mostrar las propo-

\footnotetext{
8. A destacar J. Sentaurens (1984); L.M. Brooks (1988); J. Aranda Doncel (2010), 321350; D. Becker (1989), 171-90; M.A. Flórez Asensio (2009), 463-80; B.J. García GaRCía (1989-1990), 43-64; L. Horst (2005); M.J. SANZ SERRANO (1997), 123-37.

9. J. Sentaurens (1984) vol. 2, 771-4.
} 
siciones y modelos a la comisión, y mostrarle un ensayo. Se ofrecía una joya de 30, 20 y 10 ducados a los tres primeros premios a la danza más lucida ${ }^{10}$.

La temática de estas danzas de invención era de lo más diverso, constituyendo siempre una excusa para el despliegue coreográfico o la pantomima. Una de las tipologías consagradas de las danzas de invención siempre fueron las naciones, pueblos y culturas de la tierra, por lo que llevaban consigo de vistoso y exótico en el vestuario cuando menos. Por tanto, no es extraño que los indios y los africanos entrasen a formar parte de este muestrario. ¿Qué actitud adoptó la sociedad sevillana ante los pueblos recién conocidos? ¿En qué status los representaron? Las danzas de indios se pueden clasificar dentro de la gama de danzas de naciones, en el subgrupo de las exóticas, junto a las de negros, moros, turcos o gitanos. El programa que desarrollaban las danzas estaba en sintonía con la ideología dominante, en tanto que antes de ser contratadas, las compañías debían presentar un proyecto y realizar una demostración o ensayo ante la comisión que el ayuntamiento designaba para ello. En este contexto, las danzas de temática nacional venían a alimentar la imagen de universalidad, la vocación proselitista del catolicismo: representaban a los distintos pueblos de la tierra homenajeando por igual al misterio eucarístico en su procesión. La diversidad étnica y cultural se ponía de manifiesto en el programa festivo, pero no exaltando la heterogeneidad como valor, sino todo lo contrario, al servicio de un ideal de homogeneidad religiosa.

La popularidad de la danza radicaba en sus medios expresivos, visuales y comprensibles por todos los tipos de espectadores. En ella confluían varios géneros artísticos, reflejaba los gustos estéticos locales, la memoria colectiva, las tradiciones comunes, de manera que constituía un vehículo privilegiado para la difusión de la cultura popular y de cualquier otro contenido. No sólo actuaban en la procesión del Corpus varias veces a lo largo de la jornada, sino que durante la temporada podían ser contratadas por otras fiestas religiosas particulares, por ejemplo las de otros concejos municipales satélites, conventos y parroquias, exhibiendo su espectáculo a lo largo y ancho de la sociedad y del territorio a su alcance. Ya en el siglo XVII se solían contratar las danzas por un número determinado de años para las fiestas del Corpus, Concepción, San Fernando, Patrocinio, Santas Justa y Rufina y otras. Por eso, es de esperar que desempeñaran un papel fundamental a la hora de configurar y difundir el estereotipo del indio americano y su folclore en el imaginario colectivo.

10. Ibid., vol. 2, 782-783. 


\section{AMÉRICA EN LAS DANZAS DEL CORPUS}

Las danzas relativas a los indios o a la conquista de América son numerosas en el período 1559-1659 en la ciudad de Sevilla. Las Indias como escenario de epicidad son un tema recurrente, en danzas como La conquista de las Indias (1583, 1610, 1613, 1625, 1629, 1630), La Araucana (1638 y 1642), La conquista de las Amazonas $(1589,1602,1639)$ y La conquista de los negros e indios (1634). En algunas danzas, indios y negros aparecen como una sola categoría, como pueblos domeñados por los españoles $(1599,1600,1619$, $1634)^{11}$. Los americanos se ofrecen en estas danzas homogeneizados bajo una sola categoría. Los títulos no permiten averiguar si los españoles discernían entre naciones indígenas, puesto que las denominaban indios e indias. Las Amazonas son el único pueblo que se distingue, gracias a la referencia que supone la mitología grecorromana. Se las caracteriza en 1639 como arqueras, vestidas con un peto, cotas y faldones de tela, raso, damasco y tafetán, y doblando numéricamente a los hombres que las derrotan ${ }^{12}$. El único personaje concreto que fructifica en la imaginación de los autores de danzas es Moctezuma, protagonista de tres danzas $(1592,1636,1693)^{13}$. como personaje de la teatralización fuertemente codificada de la conquista de México.

¿Se puede suponer que esta recreación de las danzas indígenas americanas hubiese absorbido algún elemento cultural propio de dichos pueblos? ¿Por el contrario se limita a modelar las concepciones y prejuicios que los españoles vertían sobre ellos? Desde luego, la documentación y el realismo no parecen ser el objetivo de estos espectáculos. Tomemos como referencia lo visual: los indios de la danza de 1593 se describen como "vestidos de plumas"14, y los aztecas en 1693 fueron caracterizados con un vestuario compuesto de enguarina, calzón sobre encaje, medias de seda de colores, zapatos bordados, capa hasta las corvas, mangotes blancos, un tocomate, una manopla emplumada, mascarillas, cabelleras largas fingidas con lino, arcos, flechas, carcajes, broqueles, alfanges y coronas con cintas ${ }^{15}$. En Córdoba, donde tenían lugar manifestaciones similares a las de Sevilla, las danzas de indios se componían de hombres vestidos con ropilla y calzón de tafetán de colores o damasco con

11. Estudio realizado sobre la relación elaborada por J. Sentaurens (1984), vol. 2, 11711225.

12. Ibid., vol. 2, 1182 .

13. Ibid., vol. 2, 794.

14. Ibid., vol. 2, 1194 .

15. Ibid., vol. 2, 1199. 
guarnición dorada, tocados de plumas rematadas con garzotas, zapatos con penachos y arcos, mascarillas con estrellas doradas, guiados por un rey que iba delante ${ }^{16}$. Queda bastante de manifiesto que el exotismo era bienvenido siempre dentro de unos determinados parámetros, utilizando un lenguaje gráfico que el público español entendiese y estuviera dispuesto a aceptar.

¿Y en cuanto a la música? ¿Se incluyeron elementos ajenos a la tradición musical europea para caracterizar a estas danzas? Nosotros mismos apenas conocemos algo sobre la música prehispánica. Nuestra información es más contextual que formal, aunque se hayan realizado aproximaciones mediante metodología etnomusicológica. Los testimonios más directos que tenemos son anécdotas salpicadas en los textos de los cronistas, como la de los indios caribes que se pusieron a la defensiva armados cuando las naves del tercer viaje de Colón intentaron atraerlos con música y danza a bordo ${ }^{17}$, señal de que los códigos coreomusicales de ambas culturas eran contrarios e irreconciliables. Gonzalo Fernández de Oviedo y Valdés en su Sumario de la Natural Historia de las Indias de 1526 describe cómo realizaban los ritos religiosos los caribes de las Antillas presididos por el cacique: éste tocaba el atambor, y los asistentes llevaban ristras de caracolillos y conchas en las piernas para que resonasen como las sonajas y cascabeles castellanos; también danzaban toda la noche cantando romances en honor a sus dioses, héroes y antepasados ${ }^{18}$. En cuanto a México, fray Bernardino de Sahagún en la Historia General de las cosas de la Nueva España menciona los instrumentos (flautas, trompetas y caracolas) que se tocaban en los sacrificios humanos aztecas, así como la supuesta danza ritual guerrera que precedió a la matanza del Templo Mayor, la cual Las Casas interpretó por el contrario como una fiesta civil y cortesana ${ }^{19}$. Incluso sabemos, por el cronista Juan Bautista Pomar, que en México existía una escuela de canto y baile. De los incas, sabemos por el cronista Garcilaso que las mujeres cantaban y sólo los hombres danzaban solemnemente, sin brincos ni saltos, enlazándose con las manos y los brazos entre ellos. El Inca se hacía acompañar de una pléyade de músicos. En el registro arqueológico, en Perú se han encontrado silbatos, trompetas ceremoniales de caracola marina, botellas silbadoras, tambores, timbales, antaras o flautas de pan, y representaciones de danzas agrícolas de hombres tomados de la mano o de

16. J. Aranda Doncel (2010), 321-350, 338.

17. M. SERNA (2003), 160.

18. Ibid., 203-204.

19. B. Barrera Parrilla (2009), 69-82. 
$\operatorname{cintas}^{20}$. Han sido hallados instrumentos de las familias idiófona, aerófona y membranófona, pero ningún cordófono ${ }^{21}$. Se cree que la escala más usada era pentatónica $^{22}$. En las pinturas murales podemos observar los contextos rituales y fúnebres en los que se empleaba la música. Por su parte, entre algunas culturas orales como los mapuches, el canto monódico era fundamental para conservar y transmitir el saber, para recoger la memoria histórica, para facilitar la interacción y cohesión social, para exaltar los homenajes y las victorias, para proyectar valores y virtudes morales y para curar en ritos terapéuticos ${ }^{23}$. Puesto que la música indígena no fue objeto del interés intelectual hasta bien entrado el siglo XIX, lamentablemente no conservamos repertorio documentable en la Edad Moderna.

Los sevillanos de la época no sabrían mucho más que aquello que escribían los cronistas de Indias porque la realidad americana formaba parte más del imaginario que de la experiencia cotidiana. No se conserva música escrita de las danzas de Corpus de Sevilla y tampoco descripciones lo bastante informativas, de modo que debemos ceñirnos a aquello que conocemos de ellas: la instrumentación que empleaban. El espectáculo visual era tan vistoso y fuera de lo común, compitiendo en originalidad y colorido, que es muy difícil que las fuentes se refieran a lo que se oía, a pesar de ser un espectáculo coreográfico, y por lo tanto musical. Los músicos propiamente dichos son muy escasos en las danzas porque se prefería rentabilizar los gastos contratando a danzantes que a su vez fueran capaces de tocar un instrumento. El más referido es el tamboril, que llevaba aparejada la flauta, tañida por la misma persona simultáneamente. Los instrumentos más habituales son de cuerda y de percusión. Violas de mano y de arco, laúdes, arpas, vihuelas (que acabarían sustituidas por guitarras andando el tiempo) y violones por una parte, y cascabeles atados a las piernas, castañuelas, panderos y sonajas por el otro. En danzas de recreación rural, se incluye la gaita, la dulzaina o la zanfoña. Sabemos que existía cierta sensibilidad hacia la caracterización instrumental de la atmósfera que se quería representar. En las ocasiones en que las danzas de cascabel recreaban escenas folclóricas populares, estos instrumentos de percusión tenían su mayor justificación puesto que en ellas, más o menos estilizadamente, se translucían rasgos de la música popular más espontánea. Ana de Medina en 1651 promete una danza "de cascaveles yntitulada La Boda de la aldea ves-

20. C. Bolaños (2009), 219-230, 224-229.

21. G. CAmacho Díaz (2010), 27-36, 30.

22. J. Subirá (1953), 939.

23. H. Molina FuenZalida (2002), 345-362. 
tida a lo Villano con muchos cascaveles y sonajas todo nuebo". A la hora de recrear la atmósfera rural española, las danzas tenían la sensibilidad de adaptarse organológicamente. No obstante, no tenemos noticias de que las danzas sevillanas de indios recurrieran a instrumentos específicos que les aportasen color, y desde luego no parece que se realizara una labor de documentación a la hora de crear estas danzas de invención. La flauta y el tamboril que empleaban eran instrumentos de tradición netamente europea, comunes a todas las danzas, y los cordófonos usados, como las guitarras, eran desconocidos en la música prehispánica.

Muy distinto es el caso de las danzas del Corpus que tenían lugar en las procesiones de la propia América colonial. Nos consta que en su contexto original las manifestaciones de la cultura popular ancestral se integraron en las fiestas urbanas bajo la forma de máscaras y danzas semejantes a las que tenían lugar en España. En América pervivió mucho tiempo el folclore prehispánico a través de este producto cultural mestizo que fueron las danzas ${ }^{24}$. Durante gran parte del siglo XVI, las danzas indígenas nutrieron la procesión del Corpus -aunque examinadas en su contenido para ajustarse al concepto español de honestidad $-^{25}$, y sólo bien entrada la centuria se comenzaron a organizar estas manifestaciones bajo los patrones españoles, aunque sin abandonar su sabor folclórico ${ }^{26}$. Entretanto, pudieron ser presenciadas y tomadas como fuente de inspiración por los españoles, en tanto que insertas en el contexto del Corpus podían ser aceptadas y aprehendidas como exóticas manifestaciones de fervor cristiano. Por ejemplo, tenemos multitud de referencias de la adaptación e inclusión de danzas sagradas y cantos de victoria de raigambre inca en las procesiones del Corpus celebradas en Perú a mediados del siglo XVI, incluyendo su instrumentación tradicional (tambores, flautas, conchas, "y otros instrumentos musicales rústicos"). En las ordenanzas municipales de El Cusco se impuso a cada parroquia la aportación de dos o tres bailes ${ }^{27}$. En fiestas urbanas como la beatificación de santa Rosa de Lima en 1668 o la inauguración de la iglesia de los Desamparados en 1672, también tuvieron lugar danzas de indios en Lima ${ }^{28}$.

La figura de Moctezuma, como se ha mencionado, fue igualmente representativa para occidentales y americanos y ha encontrado siempre un terreno

24. M.J. DE LA TORRe Molina (2007), 215-246, 233-247.

25. O. RiVERA (2009), 227-240, 229-230.

26. A. Dallal (2002), vol.4, 379.

27. M.A. Virgili Blanquet (2006), 63-78, 66-67.

28. R. Ramos Sosa (1992), 232 y 245. 
abonado en las disciplinas escénicas. En los ejemplos sevillanos nos falta información sobre el contenido de las danzas dedicadas a su persona, pero los ejemplos del Nuevo Mundo vienen a clarificar nuestras dudas y a ilustrarnos sobre qué connotaciones llevaba consigo este personaje. Ya en la temprana fecha de 1564 tuvo lugar en México una danza-pantomima que representaba la conquista de México, en la que el hijo de Cortés interpretó a su padre, con amplias significaciones políticas en contexto de rebeliones. En 1600 se escenificó de nuevo, haciéndose muy popular en el siglo XVII tanto en las cortes virreinales (con simbolismo político) como en las bodas de indios. Ya en el siglo XVIII estaba desprovisto de ritualidad política y se usaba en cualquier ocasión ${ }^{29}$. Hasta el siglo XX se han representado en el contexto del Corpus en territorio americano danzas de los Montezumas, como por ejemplo en la panameña ciudad de Los Santos y las localidades de su entorno. También en estas manifestaciones, vestigios de una costumbre tan extendida, se enfrentan los españoles y los aztecas con acompañamiento de tambor, guitarra, violín y triángulo. Pudo llegar hasta Panamá procedente de México. También han sido rastreadas danzas semejantes en Santo Domingo y en la sierra de Perú, en Guatemala y en México. Esta dramatización de la conquista puede variar de un lugar a otro, introduciendo escenas y personajes diversos, y desarrollando un texto teatral más o menos dilatado ${ }^{30}$. Ya en 1622, con motivo de la beatificación de los principales santos jesuitas, las relaciones de fiestas urbanas dan testimonio de la participación de danzas de indios contra españoles, de Moctezuma y folclóricas indígenas en las solemnidades de Puebla y Méjico ${ }^{31}$.

Esta mitología creada en torno a la figura de Moctezuma prosperó asimismo en Europa, trascendiendo el contexto del Corpus, en las obras musicales de inspiración indiana que continuarían alimentando una corriente que llega hasta el siglo XX. A lo largo de la Edad Moderna se sucedieron las fantasías novelescas sobre los imperios precolombinos con Moctezuma como protagonista, fertilizando la imaginación europea, pero cuya música sigue respondiendo a esquemas occidentales tanto como su código cultural y político ${ }^{32}$. Por citar algunos ejemplos célebres, destaquemos The Indian Queen, semiópera inglesa de John Dryden y Henry Purcell de $1694^{33}$, y Les Indes galantes, ópera-ballet francesa de Jean-Philippe Rameau de 1735.

29. A. Rubial García (2009), 541-560, 543-545.

30. E. Matos Moctezuma (1967), 71-91.

31. I. ARELLANO (2009), 27-53, 42 y 44.

32. J.R. JOUve MarTín (2008), 1-14.

33. A. NúÑEZ-RONCHI (2012), 508-533. 


\section{3. ÁFRICA EN LAS DANZAS DEL CORPUS}

Si la proyección de América en la producción coreomusical europea se produjo sobre bases nutridas por lo ideológico y lo fantástico, desde luego muy distinto es el caso de las danzas de negros. La explicación de semejante disparidad está en el contacto cultural. Las danzas de negros siempre tuvieron un modelo directo que sí estaba al alcance de los creadores coreográficos sevillanos. Aunque la esclavitud es un fenómeno extendido por todo el territorio español y todas las capas sociales, en Andalucía y el Levante se concentra su incidencia ${ }^{34}$. La población africana en Sevilla era muy nutrida desde el siglo $\mathrm{XV}$, en torno a un $3,7 \%$ de la población hispalense, pero en la segunda mitad del siglo XVI llegará al 8\%, de los cuales los subsaharianos podrían suponer un $68 \%{ }^{35}$. La Casa de Contratación era el principal centro de distribución de esclavos a nivel nacional e internacional, mercancía que aportaban principalmente los comerciantes portugueses que detentaban el monopolio de las costas africanas, pero además en la ciudad existía una enorme demanda de mano de obra esclava que absorbía el 85\% de los cautivos que permanecían en Espa$\tilde{n} a^{36}$. En Sevilla vivía un contingente numeroso de esclavos, la mayoría entre los 18 y los 30 años y tantos hombres como mujeres ${ }^{37}$, que por sus características demográficas serían proclives a la vitalidad, la sociabilidad y los ritos de atracción sexual. En la temprana fecha de 1393 fue confirmada por el Papa la fundación de una hermandad y hospital para negros en Sevilla, y se concedió a los negros el derecho de reunirse los domingos y días de fiesta ${ }^{38}$. En 1475 los reyes crearon el cargo del juez de esclavos de Sevilla, que era un negro, para regular y dirimir los asuntos y conflictos a que daban lugar los esclavos negroafricanos $^{39}$. En 1497 las actas capitulares municipales autorizaban a los negros de Sevilla a participar con sus juegos y danzas en el recibimiento de la reina ${ }^{40}$. Si durante el siglo XVI fueron Cabo Verde y Guinea las principales fuentes de esclavos portugueses y Berbería de esclavos españoles, en el siglo XVII los proveedores de Angola y Congo ganan protagonismo ${ }^{41}$. El esclavo

34. J.L. CORTÉS LÓPEZ (1989), 18-19.

35. A. Collantes de Terán (1984), A. Domínguez Ortiz (1974), 179; J.L. Cortés López (1989), 201-204. M.F. Fernández Chaves y R.M. Pérez García (2010), 5-34, 6.

36. M.F. Fernández Chaves y R.M. Pérez García (2009), 85.

37. A. Franco Silva (1979), 336.

38. I. MORENo (1997), 35 y 39.

39. A. Franco Silva (1979), 222-223.

40. L. MÉNDEZ RodRÍGUEZ (2007), 397-412, 398.

41. M. Lobo Cabrera y M.E. Torres Santana (1996), 99-116, 102. 
en el medio urbano era un objeto suntuario, utilizado en la artesanía y en el servicio doméstico ${ }^{42}$.

Nos consta, gracias a la Vida y hechos del rey don Juan II de Portugal escrita por García de Resende, que fue en Portugal donde se dieron en primer lugar las danzas cortesanas de temática negra: en la boda de Juana de Avis con Enrique IV de Castilla, en 1455, una danza fue ejecutada por doscientos hombres disfrazados de negros y cargados de oropeles y de cascabeles dorados, capitaneados por "el rey de Guinea" ${ }^{43}$. Previamente, en 1451 Leonor de Portugal había tenido en sus bodas con Federico III danzas de negros y moros ${ }^{44}$. La morisca era una danza popular de bailarines disfrazados de negros y que se difundió por las cortes europeas en los siglos XV y XVI ${ }^{45}$. Cabe pensar que esta incorporación de los negros a los festejos se produce al ritmo de la entrada de los africanos en el imaginario colectivo y en el medio social, en Portugal antes que en Sevilla.

También por la convivencia de la sociedad con esta comunidad negra, en la procesión del Corpus sevillana fueron admitidas muchas danzas de temática africana, al menos desde que tenemos registros. Se puede contabilizar 27 danzas de negros entre la mitad del siglo XVI y la del XVII, la primera en 1564. Muchas de ellas se referían directamente a Guinea, principal fuente del tráfico de esclavos en el que Sevilla tenía buena parte ${ }^{46}$, como un topónimo generalista que apuntaba a la parte de África descubierta en la Modernidad y habitada por esclavos potenciales, frente al topónimo antiguo de Etiopía ${ }^{47}$. Las danzas de negros pueden dividirse en dos grandes grupos. Algunas trataban de recrear fiestas, tomando como modelo las reuniones festivas en las que todos los sevillanos habían visto a los esclavos negros: presentan a sus integrantes en ambiente distendido y presumiblemente muy realista, como La zambra de los negros (1576, 1586), La cachumba de negros (1589), La boda del rey de Guinea (1609) o El sarao del rey de Guinea (1628); otras en cambio los presentan como vencidos por los europeos, en danzas de carácter más épico y narrativo, por ejemplo en El triunfo de Cocambur (1590), La batalla de Guinea (1614),

42. J.L. Cortés López (1989), W.D. Jr. Phillips (1990), A. Domínguez Ortiz (1950), 369428. A. Franco Silva (1984), M. Á. Ladero Quesada (1967), 63-88, G. Lora (1982), 177-191, J. SÁnchez Herrero (1980), 77-83. A. N'DAmba RabONGo (1975) y (1969), E. Del Pino (1976), 3-62.

43. A. Santos Morillo (2003), 233-255, 235.

44. P. RuSSEL (1978), 383.

45. A. Santos Morillo (2011), 23-46, 30.

46. J. Sentaurens (1984), vol. 2, 793-794.

47. B. Fra Molinero (1995), 17. 
La conquista de Guinea $(1627,1629)$ y El engaño de Guinea (1641, 1644, 1657). Otros títulos parecen ser más neutros, como Las naciones de Guinea (1606) o Los Negros. Debemos hacer constar que la temática nupcial era muy recurrente en las danzas, ambientándose en cualquier tipo de contexto, sea mitológico, exótico, pastoril, histórico... La figura de la monarquía se proyecta a menudo sobre las naciones africanas, ya sea mediante el rey de Guinea, el de Etiopía (1620) o mediante el propio rey Baltasar (1615).

Salvo excepciones, las interpretaban blancos disfrazados de africanos ${ }^{48}$. Cotarelo y Mori documenta el más temprano vestuario de una danza de negros en Toledo en 1525, el cual constaba de betún asentado con huevos y aceite para teñir las extremidades, máscaras negras, cabelleras de cáñamo, porras, flechas, navajas, argollas y cadenas ${ }^{49}$. En Córdoba, el vestuario de las danzas de negros comprendía calzones y ropillas de tafetán de colores, tocados con bonetes rojos rematados con toquillas de velo de plata con plumas y máscaras negras, y el rey llevaba un sayo de terciopelo ${ }^{50}$. Las danzas de cascabel de temática africana se caracterizaban por una instrumentación de panderos, sonajas, atabalillos y toda clase de instrumentos idiófonos de percusión. La de 1621 de Sevilla incluía "un tamboril, y una guitarra, y los cuatro con panderetes y sonajas y los otros cuatro con atabalillos, y las cuatro mujeres con sonajas y banderas" ${ }^{\prime 51}$. ¿Debemos interpretar que, como en las danzas de indios, los autores confiaban la caracterización instrumental de los africanos a su imaginación o a las demandas del público? Aunque estos factores tendrían su influencia, parece que en este caso las recreaciones se ceñían mejor a la realidad. Las sonajas eran instrumentos muy característicos de las danzas de negros, y podemos constatar que no se trata de una recreación del imaginario sevillano sino de una inclinación cultural real, porque en las cuentas de la cofradía que formaron los negros de Sevilla, la de Nuestra Señora de los Ángeles $^{52}$, conservadas del siglo XVII figuran varias anotaciones sobre compra y reparación de sonajas.

48. Se ha documentado algún caso de autor de danzas negro libre, y de alguna danza de auténticos negros que actuó en otras fiestas no eucarísticas. L.M. BRooks (1988), 237.

49. E. Cotarelo y Mori (1919), 171. Apud. F.M. Cabrera y Rivera (1935), 163-167.

50. J. Aranda Doncel (2010), 339.

51. J. SENTAURENS (1984), vol. 2, 1202.

52. V. Morabito (2000), 223-273. 


\section{RECEPCIÓN DE LAS DANZAS EXÓTICAS}

¿Qué impacto producían en el público este tipo de representaciones de la alteridad? A pesar de nuestra ignorancia en todo lo descriptivo-formal que se refiere a estas danzas, sí nos consta que las de temática exótica eran las que cosechaban más éxito ${ }^{53}$. De hecho, si sumamos tan sólo las danzas de negros, las de indios y las de amazonas ( $\sin$ contar las danzas dedicadas al resto de naciones, mucho menos numerosas), en el período rastreado por Jean Sentaurens encontramos 55 danzas $^{54}$. La suma de las danzas de naciones arroja un total de 106. Las categorías más recurrentes, la religiosa y la mitológica, no pasan de 33 cada una, y la alegórica llega al mismo nivel que las danzas de negros. Introduzcamos un gráfico que compara los grupos temáticos más numerosos, sin que abarquen la totalidad de ellos. En él se puede observar cómo las danzas de naciones representan un $24,3 \%$ del total.

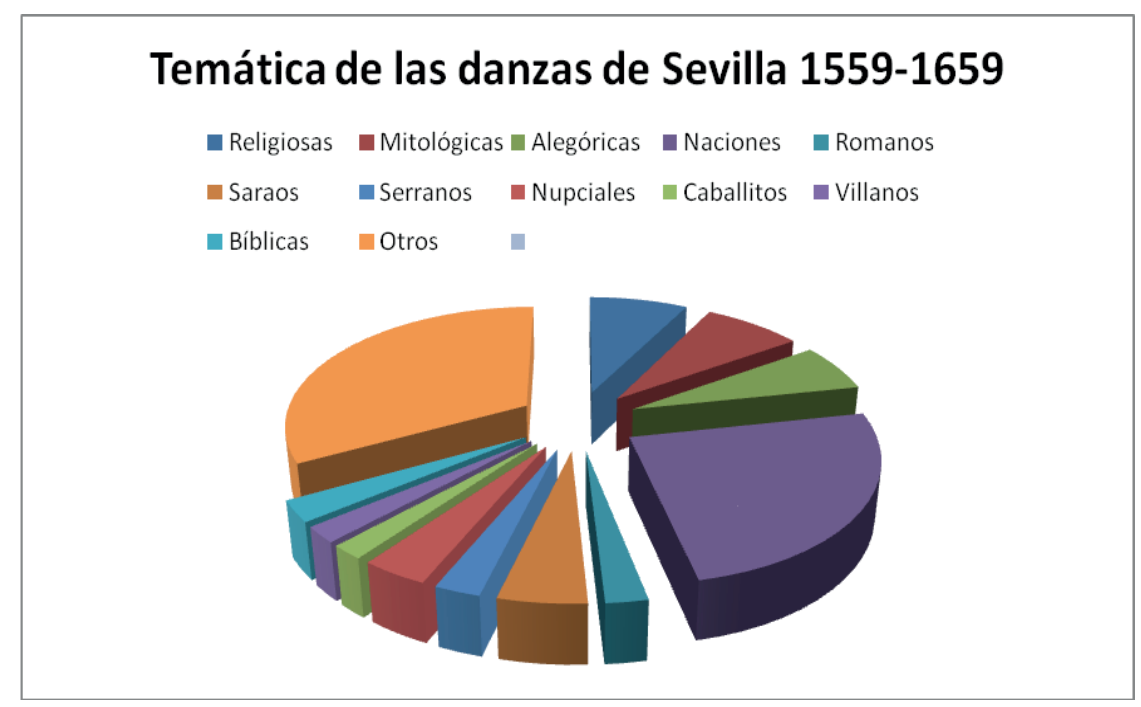

53. J. Sentaurens (1984), vol. 2, 783.

54. Hemos podido realizar estas estadísticas gracias a los magníficos apéndices de dos obras y al esfuerzo inestimable invertido por sus autores en los archivos sevillanos: J. SENTAURENS (1984), vol. 2, 1173-1225 y L.M. BROOKS (1988), 365-75. 
De todas formas, dentro del grupo de las danzas nacionales, el predominio de las naciones exóticas es abrumador: las de negros suponen un $25,5 \%$, y las de indios y amazonas otro tanto, mientras que el grupo que les sigue resulta igualmente exótico: el de los moros y turcos $(21,7 \%)$.

\section{Distribución de las danzas de naciones}

\begin{tabular}{|c|c|c|}
\hline Moros y turcos & s Amazonas & Negros \\
\hline Chinos & - Portugueses & Franceses \\
\hline Húngaros & Japoneses & Pigmeos \\
\hline
\end{tabular}

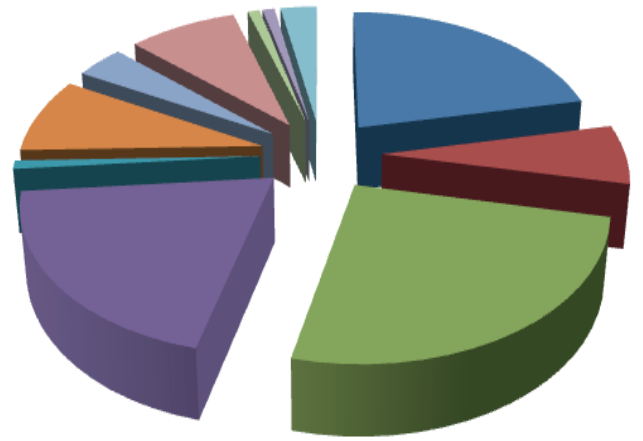

La popularidad del tema se extiende más allá de los límites de Sevilla. En el caso de la vecina ciudad de Córdoba, entre las danzas del Corpus de 16011640 también se puede contabilizar todos los años (excepto 1631 y 16381640) al menos una danza referente a las naciones (preferentemente exóticas). Incluso hay años en que todas las danzas se pueden encuadrar en esta categoría, como por ejemplo 1605, en que las danzas se denominan Morisca, Sarao de negros, Indias, Gitanas y Portugueses. En este arco cronológico, contabilizamos 12 danzas de negros (distinguiendo entre las de negros, las de $E l$ engaño de Guinea, las de Sarao de negros y una de negros naturales) y otras 12 de indios, incluyendo una de 1601 que especifica las etnias: Chichimecos y 
guacamayos $^{55}$. Incluso en Medina del Campo, tan lejana a la carrera de Indias pero nudo neurálgico en el flujo comercial peninsular, en 1593 se organiza una danza de cuatro indios y cuatro amazonas (caracterizadas con cabellos rojos, teta izquierda postiza y rostro hermoso), en 1595 una danza de negros y negras en la que se lucirían máscaras negras y se tocarían folías ellos y panderillos ellas, y en 1597 una danza de cuatro naciones en la que además de los castellanos y los turcos aparecen representados los negros y las amazonas. En la de negros de 1625, éstos aparecían como esclavos dentro de una jaula ${ }^{56}$. Incluso en la literatura el público español demandaba a los negros sus bailes tradicionales para divertirse riéndose, como sucede en la novela La industria vence desmanes, de Mariana de Carabajal ${ }^{57}$. La participación de los negros en los recibimientos de reyes en las ciudades es recurrente en la documentación ${ }^{58}$.

¿A qué se debía esta predominancia de las danzas sobre negros e indios? Puesto que los principales valores de una danza, en un proceso de creciente sofisticación, eran la vistosidad y la originalidad, pensamos que los pueblos exóticos constituían una excusa para los mayores despliegues imaginativos y las mayores licencias en cuestión coreo-musical, aunque no necesariamente respondieran a un esfuerzo de documentación de la realidad. No olvidemos que la pasión por las novedades gobernaba aquella fase de dinamismo socioeconómico, y que las actividades políticas y comerciales de España suministraban nuevo material para las creaciones ${ }^{59}$.

Resta mencionar que, además de las danzas de invención, también hay constancia de la participación de danzantes supuestamente negros en la procesión del Corpus representando el papel de diablillos. Estas figuras, al igual que la tarasca o los cabezudos (de tez blanca), representaban el desorden y el pecado que el Sacramento venía a redimir.

55. J. ARANDA Doncel (2010), 336-337.

56. A. Rojo Vega (1999), 87-89. Apud I. Mena Martín (2010), 571-586, 574-578.

57. L. MÉNDEZ RODRÍGUEZ (2007), 401.

58. Ibid., 402.

59. L.M. BROOKs (1988), 187. 


\section{5. ÁFRICA Y AMÉRICA EN LAS DANZAS PROFANAS}

Pero la música tradicional negra no era tan sólo una recreación blanca en la metrópoli hispalense, como hemos visto hasta ahora. La yuxtaposición entre la cultura musical española y la africana tuvo lugar América, a donde la mayoría de los esclavos fue dirigida, pero también en grandes metrópolis ibéricas con gran participación en el comercio esclavista. Sevilla constituye un ejemplo apetecible, por cuanto la historia de la esclavitud ha sido bien estudiada en ella y la concentración de africanos era lo bastante significativa como para conservar y realizar demostraciones públicas de su cultura originaria. A los numerosos esclavos negros se reglamentó su situación, reconociéndoseles algunos derechos, entre ellos el de poder reunirse los domingos y días de fiesta según sus costumbres ancestrales. En Sevilla, según señalan las crónicas, lo hacían desde el siglo XV en algunos días de fiesta cerca de Santa María la Blanca, en la zona que luego se llamaría de la Puerta de la Carne, con panderos, tambores y otros instrumentos de su tradición cultural autóctona. El fenómeno por el que más se conoce a la comunidad negra a través de las fuentes es por los grandes bailes profanos que organizaban en la vía pública. Estos eventos cumplían una importante función dentro de este colectivo, pues además de favorecer su socialización mantenía los lazos culturales entre ellos y con su tierra de origen, constituyendo un recurso esencial de resistencia pasiva. Incluso se ha interpretado que en sus músicas sincréticas perseguían la ridiculización de sus equivalentes españolas. Si la sociedad se lo permitía era porque de este modo toleraban mejor el cautiverio y trabajaban más ${ }^{60}$. Estos bailes públicos de carácter profano tenían una justificación económica: se llevaban a cabo para conseguir fondos para la cofradía que englobaba a los negros de la ciudad. Puesto que estos actos eran poco religiosos, no suelen aparecer referencias sobre ellos en la documentación de esta hermandad, aunque se puede encontrar algunas ${ }^{61}$. Estas fiestas que se ofrecían a los ojos de la sociedad sevillana constituyeron una ineludible fuente de inspiración coreo-musical y un marco incomparable para la simbiosis.

60. A. Santos Morillo (2011), 32.

61. I. MORENO (1997), 130. 
Se ha afirmado desde antaño que determinadas danzas del siglo de Oro adoptadas por los españoles tienen inspiración africana ${ }^{62}$ : el a ${ }^{63}$, el guineo ${ }^{64}$, el canario ${ }^{65}$, el ye-ye, el zarambeque o zumbé ${ }^{66}$, el paracumbé ${ }^{67}$, el zambapa$10^{68} \ldots$ La mayor parte de estas danzas nos son conocidas por los nombres con que en su época fueron bautizadas, sin que tengamos testimonios más concretos sobre sus evoluciones. De entre todas las danzas del Siglo de Oro, la más directamente atribuida a su origen africano es el guineo o guinea, que se transmitió a América. El diccionario de Covarrubias apenas ofrece elementos descriptivos, "movimientos prestos y apresurados", pero sí apunta a su procedencia: "pudo ser fuesse trayda de Guinea y que la dançassen primero los negros" $"$.

Al ser ésta la actividad a través de la cual se les solía representar en el teatro, los testimonios dan la impresión de que los africanos destacaban por su afición a la danza. Numerosas obras dramáticas de los siglos XVII y XVIII presentan a las comunidades negras bailando el guineo, incluso imitando la particular fonética de sus letras. Naturalmente, hay que tener presente que en el teatro del Siglo de Oro el elemento musical era indispensable para la consecución de los objetivos artísticos y comerciales que se perseguían. La música se incorpora en el desarrollo de la acción cumpliendo diversas funciones, entre ellas la caracterización de los personajes y ambientes ${ }^{70}$. La figura del negro se convierte en un estereotipo cómico desde inicios del siglo XVI con Rodrigo

62. B. Fra Molinero (1995), 38.

63. L.M. Brooks (2003), 146. J.M. Ruiz Mayordomo (2002a), vol. 8, 784.

64. El guineo se extendió como danza en Hispanoamérica desde fines del siglo XVI hasta fines del XVIII. C. Russell (2002b), vol. 6, 66.

65. El canario era un baile popular que llegó a España por vía de las islas Canarias, escala en la carrera de Indias. Se bailaba sin pareja y con un vivo zapateado, asemejándose al saltarello. En el siglo XVII pasó a formar parte de las suites instrumentales y se estilizó como danza. Se tiene constancia de él en Sevilla desde mediados del siglo XVI. G. GáLvez (2002), vol. 2, 1016.

66. El zarambeque es una danza de probada procedencia africana y gran extensión por América. En España apareció como novedad indiana en los escenarios en 1625. O. JAQUE Figueroa y M.J. Ruiz Mayordomo (2002), vol. 10, 1135.

67. El cumbé o paracumbé es una danza de textos y movimientos licenciosos, que subraya las armonías de dominante y tónica y oscila entre los compases $3 / 4$ y $6 / 8$. C. RusseLL (2002a), vol. 4, 309-311. Se convirtió en elemento musical evocador de América en la tonadilla escénica española del siglo XVIII. J.P. FernÁndEZ-CorTés (2007), 437-453, 443.

68. El zambapalo es una danza grotesca llegada a España desde América en el siglo XVI. No se tiene descripción coreográfica. M.J. Ruiz MAYORDOMo (2002b), vol. 10, 1083.

69. S. Covarrubias Orozco (1611), voz guineo.

70. C. CABallero FernándeZ-Rufete (2003), vol. 1, 677-716, 683. 
de Reinosa ${ }^{71}$, -caracterizado por medio de constantes lingüísticas, situacionales y referenciales a su condición de esclavo ${ }^{72}-$, indisociable de la música, y esto va a condicionar todas nuestras fuentes literarias. Ya desde el siglo XIII se daba por sentada la desmedida inclinación de los negros hacia la música, el baile, la fiesta y el canto. En el teatro, el negro cantaba y hacía referencias a canciones en el texto y fuera de él13. Por ejemplo, en la Novela Ejemplar cervantina El celoso extremeño, el esclavo doméstico negro llamado Luis es fácilmente engatusado por el seductor Loaísa con la promesa de clases de guitarra. Cervantes lo caracteriza con rápidas pero tópicas generalizaciones: "diera un brazo por poder abrir la puerta y escucharle más a su placer; tal es la inclinación que los negros tienen a ser músicos" "74. No obstante, también hemos de recordar que en el teatro del Siglo de Oro la música se introducía como elemento de verosimilitud, recreando las atmósferas con la mayor fidelidad posible, hasta el punto de convertirse las páginas teatrales en un yacimiento de material folclórico hoy perdido ${ }^{75}$. Y esta idea de la musicalidad de los negroafricanos estaba presente también en contextos no exactamente literarios, como en la crónica de Alonso González de Nájera a principios del siglo XVII, en que se describe a los esclavos negros como dóciles e inclinados al canto y a tocar instrumentos "alegres como sonajas, tamboriles y flautas, y aficionadísimos a guitarras, pues aún en sus tierras las hacen, aunque de extraña forma y manera de tocarlas" ${ }^{\prime 76}$.

Más allá del teatro y de Sevilla, nos consta que en 1573 ya se prohibió en Cartagena de Indias que los bailes de negros de los domingos se celebraran en lugares no autorizados o durante más tiempo del permitido, y en 1590 en Guayaquil se prohibía que se tocaran los tambores después del toque de Avemaría (por la noche) para convocar a las negras ${ }^{77}$. En 1585 los negros son los encargados de las danzas del Corpus en Lima ${ }^{78}$, y de las de otras festividades como las dedicadas a Santa Rosa de Lima (en que los propios negros desempeñaban un papel burlesco en la máscara) ${ }^{79}$ y que en 1596 también en México se celebraban bailes y certámenes de danza entre los negros, sobre todo con

71. M. García BarRanco (2010), 151-172, 155.

72. B. Fra Molinero (1995), 20.

73. A. Santos Morillo (2011), 30.

74. M. de Cervantes SaAvedra (1983), vol. II, 62.

75. C. CABALlERo FernáNDEZ-RufETE (2003), vol. 1, 684-687.

76. H. Molina FuenZalida (2002), 353.

77. L. MÉNDEZ RodRÍGUEZ (2007), 404.

78. R. Ramos Sosa (1992), 209.

79. J.C. Estenssoro (1989), 71. 
motivo del Corpus, de modo que los desórdenes a que daban lugar empujaron al virrey a restringirlos a los domingos y festivos entre el mediodía y la seis de la tarde ${ }^{80}$. También en Bolivia se registran aportaciones percusivas y coreográficas de los negros en las procesiones y festividades religiosas en el siglo XVII ${ }^{81}$.

Los tres continentes confluyeron coreográficamente hablando en la danza más popular del período. Se piensa que la zarabanda, la danza española más célebre del Siglo de Oro, tuvo su origen en América en el siglo XVI y fue recibida en Sevilla a fines de la centuria ${ }^{82}$. La zarabanda es un tema sobre el que se han vertido ríos de tinta desde sus orígenes, debido a la controversia que provocó $^{83}$. Su condición de lasciva, proclamada unánimemente por los moralistas de la época, derivaba de la implicación de los brazos y las manos, más que de la pelvis ${ }^{84}$. Las danzas europeas se caracterizan por un complejo juego de pies pero una gran pasividad del tren superior. Bailada tanto por mujeres como por parejas ya en 1599, incluía el tañido de castañuelas ${ }^{85}$. La primera noticia que tenemos de la zarabanda como canto en España es la prohibición que llevaron a cabo los alcaldes de Madrid en 1583, con pena de 200 azotes, galera y destierro. Como baile, apareció en Sevilla en 1588, donde tuvo tan buena acogida que se ejecutó en el Corpus, tanto en la procesión general como en los conventos femeninos. De su larga vida en esta ciudad dan cuenta los literatos como Cervantes y Lope de Vega, y ya era una danza de sociedad en 1618 en la corte española, y en 1625 en la francesa, aunque ya más pulida y decorosa ${ }^{86}$.

No se sabe si efectivamente la influencia americana estuvo en la base del nacimiento de la zarabanda (danza que en las suites europeas representaba a la nación española ya en el siglo XVII), pero sí se sabe que fue extraordinariamente acogida por la comunidad negra, y que ésta ejerció una enorme influencia sobre la población general, como demuestran las censuras de los moralistas $^{87}$. Por ejemplo, en la obra teatral de Simón Aguado de 1602, Los Negros, se indica que un grupo extenso de negros debe entrar en escena bailando una zarabanda con tamboriles y sonajas ${ }^{88}$.

80. C. Russell (2002b), vol. 6, 66 .

81. W. SÁNCHEZ CANEDo (2010), 115-123, 117.

82. L.M. Brooks (1988), 199.

83. D. Devoto (1966), 3-16.

84. J.M. RuIz MAYORDOMO (2003), 283-307, 288.

85. S. Covarrubias Orozco (1611), voz çarabanda.

86. C. Carretero Munita (1980), 30-35.

87. B. Fra Molinero (1995), 37.

88. J.M. Ruiz Mayordomo (2003), 302. 
Relacionada con la zarabanda está la chacona, que fue su heredera a comienzos del siglo XVII, porque ambas se bailaban sin pareja, con castañuelas y pandero ${ }^{89}$. La chacona era una danza en metro ternario, de tempo moderado, sobre un bajo ostinato y variación continua, con texto licencioso y acompañamiento de guitarra y percusión. De las calles pasaría al teatro, y de ahí a Italia y Francia, donde entró a formar parte de suites instrumentales ${ }^{90}$. Zarabanda y chacona debieron de ser danzas criollas, que llegaron a España siendo ya mestizas, remodeladas en Sevilla por los esclavos negros ${ }^{91}$. Incluso se señala que su origen fue concretamente el Perú ${ }^{92}$, aunque también se ha defendido su génesis española. Cervantes, Lope de Vega y los contemporáneos se refieren a la zarabanda, la chacona e incluso el fandango como danzas procedentes de las Indias e introducidas recientemente a fines del siglo $\mathrm{XVI}^{93}$.

Las ocasiones en que la comunidad negra tuvo oportunidad de danzar en la sociedad sevillana no se limitan al Corpus y a los bailes en la vía pública. Existen, asimismo, numerosos testimonios, aunque en general poco conocidos, sobre la forma en que los negros, especialmente los sevillanos, celebraban en la iglesia la Epifanía, su fiesta patronal debida a la figura del rey Baltasar. También el día de la Virgen de los Reyes, cuando los negros conmemoraban a su santo patrón, tenían lugar danzas en la iglesia acompañados de los ministriles de la iglesia mayor y de la atambora ${ }^{94}$, claro que esta manifestación no es extraña a la cultura española de la época, sino todo lo contrario. La danza ritual en contexto religioso se admitía bajo techo sagrado como una ofrenda solemne y tenía lugar en las principales festividades del año litúrgico, por lo que debió de ser fácil que se produjera un sincretismo entre la costumbre de las danzas sagradas o propiciatorias africanas y las danzas religiosas sevillanas, por más que fueran divergentes en estilo.

Hay que tener en cuenta que algunos de los esclavos habían sido comprados por sus dueños precisamente en virtud de sus cualidades musicales y que ejercieron la música profesionalmente. Teniendo presente que la población negra en Sevilla está más relacionada con el servicio doméstico y la exhibición suntuaria que con otra actividad económica, podemos encontrar negros tanto en las cámaras nobiliarias como en las iglesias y procesiones religio-

89. L.M. BroOKS (2003), 137-138.

90. M.C. CAÑEdo Estrada (2002), vol. 3, 524.

91. J.M. CABALlERo Bonald (1991), 166.

92. L.K. Stein (2001), voz "Spain".

93. E. Cotarelo y Mori (1919), M.C. Cañedo Estrada (2002), vol. 3, 526. M.A. Virgili BlANQueT (2006), 69.

94. I. MORENO (1997), 39-54. 
sas $^{95}$. En el siglo XVII hay testimonios de ministriles negros (intérpretes de instrumentos de viento-madera) trabajando para otros ministriles blancos o para particulares que arrendaban sus servicios. También en la sociedad criolla que se desarrollaría en América, los negros estarían muy vinculados profesionalmente a la música. Por citar algunos ejemplos, ya en 1598 existe un pleito en el consejo de Indias sobre el valor de unos esclavos negros músicos ${ }^{96}$. En 1628 el procurador de la provincia de Paraguay trajo hasta allí a 40 jesuitas junto con 8 esclavos músicos angoleños ${ }^{97}$. En 1677 fueron enviados desde Sevilla cinco negros esclavos para que sirvieran como ministriles chirimías en la catedral de Panamá ${ }^{98}$. En Brasil, los ministriles de viento y percusión que tocaban en las ceremonias religiosas y civiles, en las iglesias y las procesiones, solían ser mulatos y negros en el siglo XVIII ${ }^{99}$. Por otro lado, no pocos nobles andaluces de esclarecido linaje como el duque de Medina Sidonia tuvieron grupos de cámara que tocaban instrumentos de cuerda pulsada, compuestos por esclavos o esclavas negras e indias, desde mediados del siglo XVI ${ }^{100}$. Los esclavos valían más si cantaban o bailaban. Recibían clases de instrumento y sorprendentemente de composición, porque a los negros se les presuponían cualidades para la música y la danza. El celoso extremeño, Novela Ejemplar de Cervantes, también incluye una mención a las clases de guitarra que algunos negros esclavos de caballeros veinticuatros gozaban ${ }^{101}$. A juzgar por las cuentas internas de estas casas nobiliarias, recibían mejor formación y tratamiento que el resto de criados.

A la vista de lo dicho, todos los testimonios apuntan a que los negroafricanos continuaron cultivando su música tradicional en los bailes públicos además de aprender la tradición cristiana para ejecutarla en la iglesia y en el mundo profesional de la música al servicio de sus amos ${ }^{102}$. Por esta razón, y teniendo en cuenta que la comunidad negra vivía junto a los españoles en España y junto a españoles e indígenas en América, parece razonable sostener que se convirtieron en la correa de transmisión intercultural entre Europa, África y el Nuevo Mundo en lo que a música se refiere. Dada su capacidad de

95. R. Freund SCHWARTZ (2001), 598-619.

96. Archivo General de Indias (AGI), Escribanía, 1011B.

97. AGI, Contratación, 5403, n.1

98. AGI, Contratación, 5441, n.2, R.62.

99. R.T. DE PAUla (2006), 33-35.

100. L. GómEZ FERNÁNDEZ, (2007), 59-68.

101. L. MÉNDEZ RODRÍGUEZ (2007), 402.

102. R. Freund SchWARTZ (2001), 598-619. 
adaptación en este aspecto, si se produjeron fenómenos de fusión coreomusical, ellos fueron protagonistas privilegiados en este proceso.

\section{CONCLUSIONES}

La proyección atlántica y los contactos intercontinentales causaron un impacto en la faceta coreo-musical de la cultura hispalense, que aunque aportase más novedades a nivel intelectual que a nivel formal, sirvió para fertilizar y dinamizar la creación. Las manifestaciones coreográficas se convierten en un vehículo privilegiado para el mestizaje cultural y musical. Las danzas que las compañías profesionales crearon en Sevilla en torno a los pueblos recientemente conocidos parecen seguir la línea estética local pero se inclinan por los temas exóticos porque éstos les permiten introducir licencias e innovaciones en aras de la espectacularidad. Pero este intento de recrear la música y la danza de indios y negros necesariamente debía acabar desembocando en un verdadero sincretismo cultural que generó danzas mestizas como la chacona, la zarabanda, el guineo y otras, al inspirarse en modelos extraeuropeos reales. Si estas manifestaciones escandalizaron a sus contemporáneos fue porque introducían un código estético contrastante con el ordinario, procedente de otras culturas; pero si se difundieron con tan sorprendente rapidez y éxito fue porque se les incorporó una base de elementos familiares al sistema coreomusical hispano, que las convirtió en reconocibles, inteligibles y adoptables. En otras palabras, constituyen un temprano ejemplo de mestizaje cultural intercontinental, el cual pudo desarrollarse en el caldo de cultivo sevillano gracias al enorme desarrollo que, por razones socioeconómicas, vivía la danza en el espacio público, y también gracias a la confluencia de tradiciones que fueron catalizadas y difundidas con éxito por la comunidad esclava. 


\section{BIBLIOGRAFÍA}

Aranda Doncel, Juan: "Las danzas del Corpus en la diócesis cordobesa durante los siglos XVI y XVII", en Fermín Labarga García (coord.), Festivas demostraciones. Estudios sobre las cofradias del Santísimo y la fiesta del Corpus Christi, Instituto de Estudios Riojanos, Logroño, pp. 321-350.

Arellano Ayuso, Ignacio (2009), "Enseñanza y diversión en fiestas hagiográficas jesuitas", en Ignacio Arellano Ayuso y Robin Rice DE Molina (coords.), Doctrina y diversión en la cultura española y novohispana, Vervuert, Madrid, pp. 27-53.

BAKER, Geoffrey (2005), "Parroquia, cofradía, gremio, ayllu: organización profesional y movilidad en el Cuzco colonial", en Andrea BomBI, Juan José CARRERAS y Miguel Ángel MARÍn (coords.), Música y cultura urbana en la Edad Moderna, Universitat, Valencia, pp. 177-190.

Barrera Parrilla, Beatriz (2009), "Arte, doctrina, diversión: aspectos de la cultura española y novohispana en el Siglo de Oro. Dos versiones para una fiesta en la corte de Moctezuma. Cultura española y mirada indígena en la matanza del templo mayor", en Ignacio Arellano Ayuso y Robin Rice De Molina (coords.), Doctrina y diversión en la cultura española y novohispana, Vervuert, Madrid, pp. 69-82.

BECKER, Daniéle (1989), "Música de instrumentos, bailes y danzas en el teatro español del Siglo de Oro", Cuadernos de teatro clásico, 3, pp. 171-90.

Bermúdez, Egberto (1995), Historia de la música en Colombia: música indigena, tradicional y cultura musical en el periodo colonial, siglos XVI-XVIII, Instituto Colombiano de Cultura, Bogotá.

Bolaños, César (2009), "Música y danza en el antiguo Perú", Revista Española de Antropología Americana, 39, 1, pp. 219-230.

Brooks, Lynn Matluck (1988), The dances of the procesions of Seville in Spain's Golden Age, Reichenberger, Kassel.

- (2003), The art of dancing in seventeenth-century Spain: Juan de Esquivel Navarro and his world, University, Lewisburg.

Caballero Bonald, José Manuel (1991), Sevilla en tiempos de Cervantes, Andalucía Abierta, Barcelona.

Caballero Fernández-Rufete, Carmelo (2003), "La música en el teatro clásico", en Javier Huerta Calvo (coord.), Historia del teatro español, Gredos, Madrid, vol. 1, pp. 677-716. 
Cabrera Y Rivera, Francisco M. (1935) “Bailes negros en España”, Anales del Museo del Pueblo español, 1, pp. 163-167.

Camacho Díaz, Gonzalo (2010), "Culturas musicales del México profundo”, en Albert Recasens BARberÀ y Christian SPEnCER Espìnosa (coords.), A tres bandas. Mestizaje, sincretismo e hibridación en el espacio sonoro iberoamericano, SEACEX Akal, Madrid, pp. 27-36, 30.

Cañedo Estrada, M. Cristina (2002), “chacona”, en Emilio CASARES RodiCIO (dir. y coord.), Diccionario de la música española e hispanoamericana, SGAE, Madrid, vol. 3, p. 524.

Carretero Munita, Concepción (1980), Origen, evolución y morfología del baile por sevillanas, I Bienal de Flamenco, Sevilla.

Cervantes SaAvedra, Miguel de (1613), Novelas Ejemplares, Madrid, J. RoDRÍGUEZ-LuIS (ed.), Madrid 1983.

Collantes De Terán, Antonio (1977), Sevilla en la Baja Edad Media: la ciudad y sus hombres, Ayuntamiento, Sevilla.

CORTÉs LóPEZ, José Luis (1989), La esclavitud negra en la España peninsular del siglo XVI, Universidad, Salamanca.

Cotarelo y Mori, Emilio (1919), Colección de entremeses, loas, bailes, jácaras y mojigangas desde fines del siglo XVI a mediados del XVII, Bailly Balliére, Madrid.

Covarrubias Orozco, Sebastián (1611), Tesoro de la lengua castellana o española. Barcelona 1943, voz guineo.

Dallal, Alberto (2002), “Danza. VIII. México”, en Emilio Casares Rodicio (dir. y coord.), Diccionario de la música española e hispanoamericana, SGAE, Madrid, vol. 4, p. 379.

Devoto, Daniel (1966), “Qué es la zarabanda?”, Boletín Interamericano, 51, pp. 3-16.

Domínguez Ortiz, Antonio (1950),"La esclavitud en Castilla durante la Edad Moderna", Estudios de Historia Social de España, 11, pp. 369-428.

- (1974), El Antiguo Régimen: Los Reyes Católicos y los Austrias, Alianza, Madrid.

Eli RoDríguez, Victoria (2009a), "Influencias musicales africanas: su impacto en la música popular del Caribe", Cuadernos de música iberoamericana 16, pp. 43-58.

- (2009b), "Nación e identidaden las canciones y bailes criollos", en Historia de la música en España e Hispanoamérica, vol. 6, La música en Hispanoamérica en el siglo XIX, Fondo de Cultura Económica, México, pp. 270-311. 
Estenssoro, Juan Carlos (1989), Música y sociedad coloniales. Lima 16801830, Colnillo Blanico, Lima.

Fernández Chaves, Manuel F. y Pérez García, Rafael M. (2009), En los márgenes de la ciudad de Dios: moriscos en Sevilla, Universidad, Granada, Valencia y Zaragoza.

- (2010), "Las redes de la trata negrera: mercaderes portugueses y el tráfico de esclavos en Sevilla (c. 1560-1580)", en Aurelia MARTín CASARES y Margarita GARCÍA BARRANCO (comps.), La esclavitud negroafricana en la historia de España. Siglos XVI y XVII, Comares, Granada, pp. 5-34.

FERnÁNDEZ-CORTÉs, Juan Pablo (2007), "Sonsonetes y cumbés: aproximación a las relaciones de la tonadilla escénica con el nuevo mundo a partir de algunas obras de Luis Misón (ca. 1720-1766) y Blas de Laserna (17511816)", en María Gembero Ustárroz y Emilio Ros-FÁbregas (coords. y eds.), La música y el Atlántico. Relaciones musicales entre España y Latinoamérica, Universidad, Granada, pp. 437-453.

FlóRez Asensio, María Asunción (2009), "Memoria de las danzas que podrán salir en la procesión del Santísimo deste presente año. Danzas y bailes en el Corpus madrileño durante los siglos XVI y XVIII", Revista de Musicología, XXXII, 2, pp. 463-80.

Fra Molinero, Baltasar (1995), La imagen de los negros en el teatro del Siglo de Oro, Siglo XXI; Madrid.

Franco Silva, Alfonso (1979), La esclavitud en Sevilla y su tierra a fines de la Edad Media, Diputación Provincial, Sevilla.

- (1984), La esclavitud en Andalucía al término de la Edad Media, Madrid. Freund Schwartz, Roberta (2001), En busca de liberalidad. Music and musicians in the courts of the Spanish nobility, 1470-1640, University, Iowa. Gálvez, G. (2002), "Canario", en Emilio Casares Rodicio (dir. y coord.), Diccionario de la música española e hispanoamericana, SGAE, Madrid, vol. 2, p. 1016.

García BARRANCO, Margarita (2010), "Correlaciones y divergencias en la representación de dos minorías: negroafricanos y moriscos en la literatura del Siglo de Oro", en Aurelia Martín CASARES y Margarita García BARRANCO (comps.), La esclavitud negroafricana en la historia de España. Siglos XVI y XVII, Comares, Granada, pp. 151-172.

García GarcíA, Bernardo José (1989-1990), "El alquiler de hatos de comedia y danzas en Madrid a principios del siglo XVII", Cuadernos de Historia Moderna, 10, pp. 43-64. 
Gembero Ustárroz, María (2000), "Las relaciones musicales entre España y América a través del Archivo General de Indias de Sevilla", en Gérard BORRÁS (comp.), Músicas, sociedades y relaciones de poder en América Latina, Universidad, Guadalajara, pp. 128-142.

- (2007a), "Circulación de libros de música entre España y América (14921650): notas para un estudio", en Iain FenLON y Tess KNIGHTON (eds.), Early Music Printing and Publishing in the Iberian World, Reichenberger, Kassel, pp. 147-177.

- (2007b): "Migraciones de músicos entre España y América (siglos XVI-XVIII): estudio preliminar", en María Gembero Ustárroz y Emilio Ros-FÁbregas (coords. y eds.), La música y el Atlántico. Relaciones musicales entre España y Latinoamérica, Universidad, Granada, pp. 17-58. Gómez FernánDEZ, Lucía (2007), "El mecenazgo musical de la casa de Medina Sidonia y el Nuevo Mundo en el siglo XVI", en María Gembero UstÁrRoz y Emilio Ros-FÁBregas (coords. y eds.), La música y el Atlántico. Relaciones musicales entre España y Latinoamérica, Universidad, Granada, pp. 59-68.

Horst, Louis (2005), Interpretación de las danzas del Renacimiento y el Barroco, Intervalic, Madrid.

JAQUe Figueroa, Osvaldo y Ruiz Mayordomo, María José (2002), "zarambeque", en Emilio Casares Rodicio (dir. y coord.), Diccionario de la música española e hispanoamericana, SGAE, Madrid, vol. 10, p. 1135.

Jouve MarTín, José Ramón (2008), "Incas y aztecas en la imaginación transatlántica: teatro, música y memoria en The Indian Queen de John Dryden y Henry Purcell", Hispanófila, 154, pp. 1-14.

LADERO QueSADA, Miguel Ángel (1967), "La esclavitud por guerra a fines del siglo XV: el caso de Málaga," Hispania, 105, pp. 63-88.

Lobo Cabrera, Manuel y Torres Santana, M. Elisa (1996), "Los otros a partir de la obra de Domínguez Ortiz", Manuscrits, 14, pp. 99-116.

LorA, Guillermo (1982), "Notas sobre el comercio de esclavos en Córdoba a fines del siglo XV," Actas 11 Coloquio de Historia Medieval andaluza, Diputación Provincial, Sevilla, pp. 177-191.

Matos Moctezuma, Eduardo (1967), "La danza de los montezumas", Anales del Museo Nacional de México, 18, pp. 71-91.

Mena Martín, Ismael (2010), "Danzas del Corpus Christi en Medina del Campo. Siglos XVI y XVII”, en Fermín Labarga García (coord.), Festivas demostraciones. Estudios sobre las cofradías del Santísimo y la fiesta del 
Corpus Christi, Instituto de Estudios Riojanos, Logroño, pp. 571-580. MÉNDEZ Rodríguez, Luis (2007), "Bailes y fiestas de negros. Un estudio de su representación artística", Archivo Hispalense, 273-275, pp. 397-412. Molina Fuenzalida, Héctor Eduardo (2002), "El canto mapuche en los cronistas del siglo XVI y XVII", en Ángel Baldomero Espina Barrio (ed.), Antropología en Castilla y León e Iberoamérica, IV. Cronistas de Indias, Universidad, Salamanca, pp. 345-362.

Morabito, Vittorio (2000), "San Benedetto il Moro, da Palermo, protettore degli africani di Siviglia, della penisola iberica e d'America latina", en Berta Ares Queija y Alessandro Stella (coords.): Negros, mulatos y zambaigos. Derroteros africanos en los mundos ibéricos, CSIC, Sevilla, pp. 223-273.

Moreno, Isidoro (1997), La antigua hermandad de los negros de Sevilla: etnicidad, poder y sociedad en 600 años de historia, Universidad, Sevilla.

N'Damba Rabongo, A. (1969), "Les esclaves a Séville a I'époque de Philippe III," inédito, Toulouse.

- (1975), "Les esclaves a Cordove au début du XVIIe siécle (1600-1621). Provenance et condition sociales", Tesis doctoral inédita.

Paula, R. T. de (2006), Música e Representação nas Cerimônias de Morte em Minas Gerais (1750-1827). Reflexões para o estudo da memória sonora na festa, Minas Gerais.

PhilliPs, William. D. Jr. (1990), Historia de la esclavitud en España, Playor, Madrid.

Pino, Enrique del (1976), “La esclavitud en Málaga”, Jábega, 14, pp. 3-62.

Ramos Sosa, Rafael (1992), Arte festivo en Lima virreinal, Consejería de Cultura, Sevilla.

Rivera, Octavio (2009), "Danza, fiesta y espectáculo teatral en Nueva España en el siglo XVI", en Ignacio Arellano Ayuso y Robin Rice de Molina (coords.), Doctrina y diversión en la cultura española y novohispana, Vervuert, Madrid pp. 227-240.

Rojo Vega, Anastasio (1999), Fiestas y comedias en Valladolid. Siglos XVIXVII, Ayuntamiento, Valladolid.

Rubial García, Antonio (2009), "Moctezuma y la Malinche, los reyes de América. Mito y fiesta en la Nueva España barroca", en Manuel FernánDEZ Chaves, Carlos-Alberto González SÁnchez y Natalia Maillard Álvarez (coords.), Testigo del tiempo, memoria del universo, Rubeo, Barcelona, pp. 541-560. 
Ruiz Mayordomo, María José (2002a), "pie de gibao", en CASAREs Rodicio (dir. y coord.): Diccionario de la música española e hispanoamericana, Madrid 2002, vol. 8, p. 784.

- (2002b), "zambapalo", en Emilio Casares Rodicio (dir. y coord.), Diccionario de la música española e hispanoamericana, SGAE, Madrid, vol. 10, p. 1083.

- (2003), "Jácara y zarabanda son una mesma cosa", Edad de Oro, 22, pp. 283-307.

Russell, Craigh (2002a), "cumbé", en Emilio Casares Rodicio (dir. y coord.), Diccionario de la música española e hispanoamericana, SGAE, Madrid, vol. 4, pp. 309-311.

- (2002b), "guineo", en Emilio CASARES Rodicio (dir. y coord.), Diccionario de la música española e hispanoamericana, SGAE, Madrid, vol. 6, p. 66.

Russell, Peter (1978), "La poesía negra de Rodrigo de Reinoso", en Temas de La Celestina y otros estudios. Del Cid al Quijote, Ariel, Barcelona 1978. SÁnchez CANEdo, Walter (2010), "Sin purezas y con mezclas. Las cambiantes identidades sonoras negro-africanas en Bolivia", en Albert RECASENS Barberì y Christian Spencer Espìnosa (coords.), A tres bandas. Mestizaje, sincretismo e hibridación en el espacio sonoro iberoamericano, SEACEX Akal, Madrid, pp. 115-123.

Sánchez Herrero, José (1980), "Cádiz, plaza del comercio de esclavos a fines del siglo XV", Gades, 5, pp. 77-83.

Santos Morillo, Antonio (2003), "Primeras manifestaciones de la lengua de negro en la literatura ibérica: comienzo de un estereotipo", Philologia hispalensis, 17, 1, pp. 233-255.

- (2011), "Caracterización del negro en la literatura española del siglo XVI", Lemir, 15, pp. 23-46.

Sanz Serrano, María Jesús (1997), "El Corpus de Sevilla a mediados del siglo XVI. Castillos y danzas", Laboratorio de Arte, 10, pp. 123-138.

Sentaurens, Jean (1984), Seville et le theatre de la fin du Moyen Age a la fin $d u$ XVIIe siècle, Presses Universitaires de Bordeaux, Lille.

Serna, M. (ed.) (2003), Crónicas de Indias. Carta del tercer viaje de Colón (1498), Madrid.

Stein, L. K. (2001), "Spain. Later 16th century to mid-18"th", en Stanley SADIE (ed.), The New Grove Dictionary of Music and Musicians, Grove`s Dictionaries, Londres, $2^{\mathrm{a}}$ ed, voz "Spain". 
Subirá, José (1953), Historia de la música española e hispanoamericana, Salvat, Barcelona.

Torre Molina, María José de la (2007), “Jugar armonías y ostentar elogios: la música en las fiestas limeñas de proclamación real (1747-1790)”, en María Gembero Ustárroz y Emilio Ros-Fábregas (coords. y eds.), $L a$ música y el Atlántico. Relaciones musicales entre España y Latinoaméri$c a$, Universidad, Granada, pp. 215-246.

Virgili Blanquet, María Antonia (2006), "Evangelización y música en la América hispana. Presencia de la música polifónicas europea en el siglo XVI y asimilación de elementos indígenas", en Jesús Varela Marcos y María Montserrat León Guerrero (coords.), Actas del Congreso Internacional "V Centenario de la Muerte del Almirante". Cristóbal Colón y el descubrimiento del Nuevo Mundo. Universidad, Valladolid, pp. 63-78.

Waisman, Leonardo J. (2005), "La música en la definición de lo urbano: los pueblos de indios americanos", en Andrea Bombi, Juan José CARreras y Miguel Ángel Marín (coords.), Música y cultura urbana en la Edad Moderna, Universitat, Valencia, pp. 159-175.

WILDE, Guillermo (2010), "Entre la duplicidad y el mestizaje: prácticas sonoras en las misiones jesuíticas de Sudamérica", en Albert ReCASENS BARBERÀ y Christian SPENCER Espìnosa (coords.), A tres bandas. Mestizaje, sincretismo e hibridación en el espacio sonoro iberoamericano, SEACEX Akal, Madrid 2010, pp. 103-112. 